\title{
Pattern of Suicidal Poisoning Cases Admitted to Menoufia Poison Control Center (MPCC) over Two Years (2013-2014)
}

\author{
Ola Abd elhady Sweilum and Fatma Shaban Kandeel ${ }^{1}$ \\ ${ }^{1}$ Department of Forensic Medicine And Clinical Toxicology, Faculty of Medicine, Menoufia University, Menoufia, \\ Egypt.
}

\begin{abstract}
Suicide is one of the most important public health problems worldwide especially among teenagers and adults under 35 years old. Poisoning is a common method of suicide, especially in the developing countries. The aim of this work is to evaluate the suicidal poisoning problem among patients attending at the Menoufia Poison Control Center (MPCC) at Menoufia University Hospital over two years (from the first of January 2013 to the end of December 2014), The study showed that The total number of suicidal poisoning cases arrived at Menoufia Poison Control Center at Menoufia University Hospital over the two years of study (2013 and 2014) was 1240 patients which represented $28.46 \%$ of the total number of poisoning cases arrived at the same period (4357cases). Suicidal poisoning was more common among females, (73.55\%). Patients from urban areas represented 56.85\%. 64.92\% of patients were single, the most vulnerable age group was 18-30 years old, Pesticides were the most commonly used substance (45.32\%). Family conflict represented $(45.56 \%)$ of causes, followed by educational problems (15.00\%), financial (14.52\%), romantic causes $(11.29 \%)$, unknown cause (8.95\%) and lastly psychiatric disease (4.60\%). $57.5 \%$ of cases of suicidal poisoning were classified as mild according to poisoning severity score.
\end{abstract}

Keywords Suicide, demographic, severity score, Poisoning.

\section{Introduction}

S uicide is one of the most important public health problems worldwide especially among teenagers and adults under 35 years old (Aggarwal 2009). The World Health Organization (WHO) defines suicide as the deliberate act of killing oneself. Rates of suicide have increased by 60\% from the 1960s to 2012 and these increases seen primarily in the developing world according to the World Health Organization (WHO)( Hawton and van Heeringen, 2009, WHO 2012)

Suicide rates in Africa (0.5\%) considered to be the least, compared to other continents (South-East Asia 1.9\% Americas 1.2\% and Europe 1.4\%) (Värnik, 2012).

Poisoning is a common method of suicide, especially in the developing countries and it has become an increasingly common response to emotional distress in young adults (Vijayakumar 2004). Suicidal poisoning is now one of the most frequent reasons for emergency hospital admission (Gunnell, et al., 1996). Drug overdose is commonly taken for suicidal poisoning in developed countries (Michel et al., 2000).
There is no official statistics for the number of suicidal cases in Egypt, as suicidal cases are underreported due to both religious and social considerations. (WHO 2011).

The aim of this work is to evaluate the suicidal poisoning problem among patients attending the Menoufia Poison Control Center at Menoufia University Hospital (MPCC) over two years ( From the first of January 2013 to the end of December 2014), through analyzing the socio-demographic data, risk factor(s), circumstances and motives, common substances used, severity of poisoning and outcome of these cases.

\section{Patients and methods}

This was a retrospective study conducted on all suicidal poisoning patients attending at Menoufia Poison Control Center (MPCC) during the period from $1^{\text {st }}$ of January 2013 to the end of December 2014.

After obtaining ethical approval from the Ethical Committee at Menoufia University Hospital. Data were collected from patients' hospital records using a questionnaire developed for this purpose after taking approval from the director of MPCC and all 
records were kept anononymous to ensure confidentiality of records and with conflict of interest. Data were collected including socio-demographic data, motives for attempting suicide, type of substance used, severity of poisoned cases, (severity of poisoning was classified according to poisoning severity score (Persson et al., 1998) and their outcome.

Persson et al., (1998) Poisoning severity score

\begin{tabular}{|l|l|}
\hline $\begin{array}{l}\text { Severity } \\
\text { grade }\end{array}$ & Clinical manifestations \\
\hline Non (0) & $\begin{array}{l}\text { No symptoms or signs related to } \\
\text { poisoning. }\end{array}$ \\
\hline Mild (1) & $\begin{array}{l}\text { Mild, transient and spontaneously } \\
\text { resolving symptoms e.g. mild GIT } \\
\text { manifestations. }\end{array}$ \\
\hline $\begin{array}{l}\text { Moderate } \\
\text { (2) }\end{array}$ & $\begin{array}{l}\text { Pronounced or prolonged symptoms as } \\
\text { aggravated } \\
\text { manifestations. }\end{array}$ \\
\hline Severe (3) & $\begin{array}{l}\text { Severe or life threatening symptoms as } \\
\text { loss of consciousness, convulsions or } \\
\text { respiratory failure. }\end{array}$ \\
\hline Fatal (4) & $\begin{array}{l}\text { Death, although it is understood that } \\
\text { death is not a grade of severity but an } \\
\text { outcome. }\end{array}$ \\
\hline
\end{tabular}

\section{Statistical Analysis}

Data were tabulated and statistically analyzed using Statistical Package for the Social Sciences (SPSS) for windows version 16.0. Categorical data were expressed as number and percentage and were compared using chi square test. P-value of 0.05 or less is considered significant and P-value of 0.01 or less is considered highly significant.

\section{Results}

The total number of suicidal poisoning cases arrived at Menoufia Poison Control Center at Menoufia University Hospital over the two years of study (2013 and 2014) was 1240 patients which represented $28.46 \%$ of the total number of poisoning cases arrived at the same period (4357cases).

It was noticed that $45.3 \%$ of patients aged between 18 - 30 years, followed by the age group 7 18 years (39.8\%). Age groups 30 - 40, 40 - 50, and 5060 years were $9.5 \%, 3.1 \%$ and $2 \%$ respectively. The lowest percent was among age group above 60 years $(0.24 \%)$. The mean age for all cases was 23.07 \pm 9.21 years (Table 1 ).

Regarding sex, females were more vulnerable than males for attempting suicidal poisoning (73.55\% females and $26.45 \%$ males). Patients from urban areas represented $56.85 \%$ and those from rural areas represented $43.15 \%$ of all cases. As regards marital status, $64.92 \%$ of patients were single (at high risk) while $30.73 \%$ were married and the least were divorced or widow which constituted $3.06 \%$ and $1.29 \%$ respectively of all patients (Table 1 ).
In the age group 7-18 years, females' suicide attempts using poisoning were more than males and the difference was statistically significant. In all other age groups the suicide attempts using poisoning were more among males than females and this difference was statistically significant among age groups; 18-30, 4050 and 50-60 (Table 2).

As regards type of toxic substances, suicidal poisoning was most commonly attempted using pesticides $(45.32 \%$ of all cases which were mainly anticholinesterase poisoning ( $71.2 \%)$ followed by cases of zinc phosphide poisoning (17.8\%) and the least was oral anticoagulant rodenticide (11\%)), followed by antipsychotics, sedative hypnotics, analgesics, household products, oral hypoglycemic, other drugs, digitalis and finally by unknown material (11.45\% and11.13\%, 8.39\%, 6.45\%, 6.29\%, 3.79\%, $3.55 \%, 2.02 \%$ and $1.61 \%$ respectively) (Figure1). The use of household, Pesticides, analgesics, and unknown agents were more common among males, although this difference was not statistically significant except for pesticide (highly significant difference p-value $<0.001$ ). On the other hand, the use of, antipsychotics, sedatives, bronchodilators, digitalis, oral hypoglycemic and other drugs were more common among females and this difference was only statistically significant with bronchodilators and oral hypoglycemic (Table 3).

Oral ingestion was the main route of exposure to poisonous substance (99.68\%) while vaginal insertion of poisonous substance( zinc phosphide poison) was found in three cases $(0.24 \%)$. Only one case injected kerosene into her left arm causing local complications.

As regards motives for suicidal attempts (from history), it was noticed that family conflict was the most common cause (45.65\%), followed by educational problems, financial problems, romantic, unknown cause (patients did not tell the motive) and lastly psychiatric disease (15.00\%, 14.52\%, 11.29\%, $8.95 \%$ and $4.60 \%$ respectively) (figure 2 ). Educational problem as a motive for suicidal poisoning was significantly more common among females than females, while unknown motive were significantly more common among males (Table 4). Educational problem was significantly the most common one at the age group 7-18 years, while the family conflict was significantly the most common motive for suicide poisoning at the age groups 18-30, 30-40 and 40-50 years. Family conflict, financial and unknown cause were significantly common motives in age group 50-60 years. Above 60 years the family conflict, financial and psychiatric motives were equally causing suicidal poisoning (the difference was not significant) (Table 5)

According to the poisoning severity score at time of arrival (Person et al.,1998) 57.5\% of cases of suicidal poisoning were classified as mild, $27.4 \%$ moderate cases, $7.9 \%$ severe cases and $7.18 \%$ of cases had no symptoms; only $13.15 \%$ of all cases needed intensive care unit admission (Figure 3).

57 patients (4.6\%) gave a history of psychiatric disorders, and were evaluated by a psychiatrist in the poisoning ward who concluded that the most important psychopathologies in these patients 
were found to be major depression followed by adjustment disorder and personality disorder.

The majority of patients (87\%) were admitted to the Toxicology department while only $13 \%$ required admission to the Intensive Care Unit (ICU) (Figure 4).

The majority of patients (93.7\%) were completely cured and discharged home. $3.4 \%$ of cases were self-discharged against medical advice before completion of treatment. The mortality rate was $2.9 \%$; $69.5 \%$ of them died from pesticide poisoning, followed by digitalis and antipsychotic drug overdose (11.1\% each), sedative-hypnotic (5.5\%), and lastly corrosive poisons $(2.8 \%)$ (Figure 5) and these cases were represented with severe clinical manifestations with history of intake of toxic doses and that was confirmed with available toxic level in the laboratory. Cases of antipsychotics and sedative -hypnotics came with grade IV toxic coma and arrested in the emergency department and admitted to ICU after Cardiopulmonary resuscitation and died few hours later. Cases died from pesticide poisoning were mainly due to zinc phosphide poisoning who presented with severe cardiac depression and the rest were due to organophosphorous poisoning who presented with severe clinical manifestations and arrested inspite of antidotal therapy. Cases of digitalis poisoning died from fatal cardiac arrhythmias inspite of supportive therapy and finally the single case of corrosives was died due to respiratory complications.

Table1: Distribution of Suicidal Poisoning Cases Admitted to Menoufia Poison Control Center (MPCC) at Menoufia University Hospital over two years (2013\&2014) as regards Socio-Demographic data

\begin{tabular}{|l|l|l|c|}
\hline \multirow{2}{*}{ Socio-Demographic data } & $\begin{array}{c}\text { Number } \\
\text { Total =1240 }\end{array}$ & \% \\
\hline Age Group & $7-18$ & 494 & $39.84 \%$ \\
\cline { 2 - 4 } & $18-30$ & 562 & $45.32 \%$ \\
\cline { 2 - 4 } & $30-40$ & 118 & $9.52 \%$ \\
\cline { 2 - 4 } & $40-50$ & 38 & $3.06 \%$ \\
\cline { 2 - 4 } & $50-60$ & 25 & $2.02 \%$ \\
\cline { 2 - 4 } & $>60$ & 3 & $0.24 \%$ \\
\hline Sex & Male & 328 & $26.45 \%$ \\
\cline { 2 - 4 } & Female & 912 & $73.55 \%$ \\
\hline Marital Status & Urban & 705 & $56.85 \%$ \\
\cline { 2 - 4 } & Rural & 535 & $43.15 \%$ \\
\cline { 2 - 4 } & Married & 381 & $30.92 \%$ \\
\cline { 2 - 4 } & Divorced & 38 & $3.06 \%$ \\
\cline { 2 - 4 } & Widowed & 16 & $1.29 \%$ \\
\hline
\end{tabular}

Table2: Chi Square Statistical analysis of Suicidal Poisoning Cases Admitted to Menoufia Poison Control Center (MPCC) over two years $(2013 \& 2014)$ as regards different age groups and gender

\begin{tabular}{|l|l|l|l|l|l|l|}
\hline \multirow{2}{*}{ Age Group } & \multicolumn{2}{|c|}{ Male } & \multicolumn{2}{c|}{ Female } & \multirow{2}{*}{ Chi Square } & \multirow{2}{*}{ P Value } \\
\cline { 2 - 6 } & $\mathbf{N}$ & $\mathbf{\%}$ & $\mathbf{N}$ & $\mathbf{\%}$ & & \\
\hline $7-18$ & 74 & 22.56 & 420 & 46.05 & 7.453 & $<0.001^{* *}$ \\
\hline $18-30$ & 180 & 54.88 & 382 & 41.89 & 4.054 & $<0.001^{* *}$ \\
\hline $30-40$ & 39 & 11.89 & 79 & 8.66 & 1.709 & 0.088 \\
\hline $40-50$ & 20 & 6.10 & 18 & 1.97 & 3.716 & $<0.001^{* *}$ \\
\hline $50-60$ & 13 & 3.96 & 12 & 1.32 & 2.926 & $0.003^{* *}$ \\
\hline$>60$ & 2 & 0.61 & 1 & 0.11 & 1.581 & 0.114 \\
\hline Total & 328 & 100 & 912 & 100 & & \\
\hline
\end{tabular}

$* *=$ Highly significant $(P$ value $<0.01)$ 
Table3: Chi Square Statistical analysis of Suicidal Poisoning Cases Admitted to Menoufia Poison Control Center (MPCC) over two years (2013\&2014) as regards gender and type of poison

\begin{tabular}{|l|l|l|l|l|l|l|}
\hline \multirow{2}{*}{ Type of poison } & \multicolumn{2}{c}{ Male } & \multicolumn{2}{c|}{ Female } & \multirow{2}{*}{ Chi square } & \multirow{2}{*}{ p Value } \\
\cline { 2 - 6 } & $\mathbf{N}$ & $\mathbf{\%}$ & $\mathbf{N}$ & $\mathbf{\%}$ & & 0.073 \\
\hline Household & 28 & 8.54 & 52 & 5.70 & 1.792 & 0.106 \\
\hline Other Drugs & 7 & 2.13 & 37 & 4.06 & 1.614 & $<0.001^{* *}$ \\
\hline Pesticide & 181 & 55.18 & 381 & 41.78 & 4.183 & 0.202 \\
\hline Analgesics & 33 & 10.06 & 71 & 7.79 & 1.275 & 0.053 \\
\hline Antipsychotic & 28 & 8.54 & 114 & 12.5 & 1.933 & 0.082 \\
\hline Sedatives-hypnotic & 28 & 8.54 & 110 & 12.06 & 1.741 & 0.717 \\
\hline Unknown & 6 & 1.83 & 14 & 1.54 & 0.363 & $0.005^{* *}$ \\
\hline Bronchodilator & 10 & 3.05 & 68 & 7.45 & 2.820 & 0.231 \\
\hline Digitalis & 4 & 1.22 & 21 & 2.30 & 1.197 & $0.001^{* *}$ \\
\hline Oral Hypoglycemic & 3 & 0.91 & 44 & 4.82 & 3.180 & \\
\hline Total & 328 & 100 & 912 & 100 & & \\
\hline
\end{tabular}

$* *=$ Highly significant $(P$ value $<0.01)$

Table 4: Chi Square Statistical analysis of Suicidal Poisoning Cases Admitted to Menoufia Poison Control Center (MPCC) over two years (2013\&2014) as regards motives and gender

\begin{tabular}{|l|l|l|l|l|l|l|}
\hline \multirow{2}{*}{ Motives } & \multicolumn{2}{c|}{ Male } & \multicolumn{2}{c|}{ Female } & \multirow{2}{*}{ Chi square } & \multirow{2}{*}{ p Value } \\
\cline { 2 - 6 } & N & $\mathbf{\%}$ & N & \% & & \\
\hline Educational & 33 & 10.06 & 153 & 16.78 & 2.921 & $0.003^{* *}$ \\
\hline Family Conflict & 147 & 44.82 & 419 & 45.94 & 0.351 & 0.726 \\
\hline Financial & 55 & 16.77 & 125 & 13.70 & 1.350 & 0.177 \\
\hline Romantic & 31 & 9.45 & 109 & 11.95 & 1.227 & 0.220 \\
\hline Unknown & 45 & 13.72 & 66 & 7.24 & 3.527 & $<0.001^{* *}$ \\
\hline Psychiatric & 17 & 5.18 & 40 & 4.39 & 0.591 & 0.554 \\
\hline Total & 328 & 100 & 912 & 100 & & \\
\hline
\end{tabular}

**= Highly significant $(P$ value $<0.01)$

Table 5: Chi Square Statistical analysis of Suicidal Poisoning Cases Admitted to Menoufia Poison Control Center (MPCC) over two years (2013\&2014) as regards motives and age

\begin{tabular}{|c|l|l|l|l|l|l|l|l|l|l|l|l|l|l|l|}
\hline Age & \multicolumn{2}{|c|}{ Educational } & \multicolumn{2}{|c|}{$\begin{array}{c}\text { Family } \\
\text { Conflict }\end{array}$} & \multicolumn{2}{|c|}{ Financial } & \multicolumn{2}{c|}{ Romantic } & \multicolumn{2}{c|}{ Psychatric } & \multicolumn{2}{c|}{ Unknown } & $\begin{array}{c}\text { Chi } \\
\text { Square }\end{array}$ & p value \\
\hline $7-18$ & 180 & $36.4 \%$ & 173 & $35.0 \%$ & 32 & $6.5 \%$ & 79 & $16.0 \%$ & 6 & $1.2 \%$ & 24 & $4.9 \%$ & 360.30 & $<0.001^{* *}$ \\
\hline $18-30$ & 6 & $1.1 \%$ & 317 & $56.4 \%$ & 94 & $16.7 \%$ & 57 & $10.1 \%$ & 34 & $6.1 \%$ & 54 & $9.6 \%$ & 168.90 & $<0.001^{* *}$ \\
\hline $30-40$ & 0 & $0 \%$ & 52 & $44.1 \%$ & 39 & $33.1 \%$ & 4 & $3.4 \%$ & 8 & $6.8 \%$ & 15 & $12.7 \%$ & 61.11 & $<0.001^{* *}$ \\
\hline $40-50$ & 0 & $0 \%$ & 16 & $42.1 \%$ & 7 & $18.4 \%$ & 0 & $0.00 \%$ & 4 & $10.5 \%$ & 11 & $28.9 \%$ & 31.33 & $<0.001^{* *}$ \\
\hline $50-60$ & 0 & $0 \%$ & 7 & $28.0 \%$ & 7 & $28.0 \%$ & 0 & $0.00 \%$ & 4 & $16.0 \%$ & 7 & $28.0 \%$ & 29.20 & $<0.001^{* *}$ \\
\hline$>60$ & 0 & $0 \%$ & 1 & $33.3 \%$ & 1 & $33.3 \%$ & 0 & $0.00 \%$ & 1 & $33.3 \%$ & 0 & $0.00 \%$ & 7.29 & 0.200 \\
\hline
\end{tabular}

$* *=$ Highly significant $(P$ value $<0.01)$ 
Figure 1: Type of poisonous substance

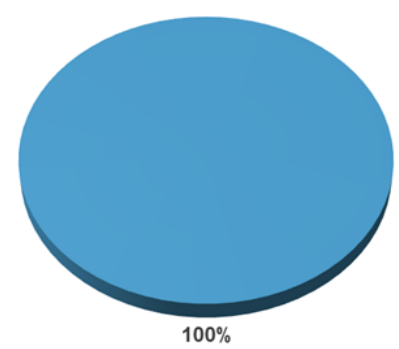

Figure 1: Distribution of Suicidal Poisoning Cases Admitted to Menoufia Poison Control Center (MPCC) at Menoufia University Hospital over two years $(2013 \& 2014)$ as regards type of poisonous substances.

\section{Figure 3: Severity of poisoning}

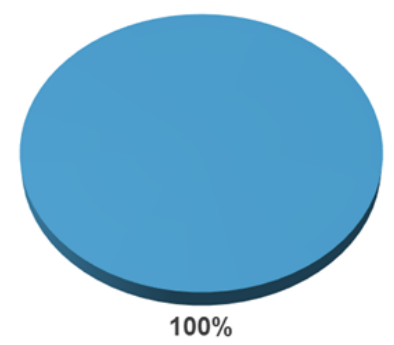

Figure 3: Distribution of Suicidal Poisoning Cases Admitted to Menoufia Poison Control Center (MPCC) at Menoufia University Hospital over two years $(2013 \& 2014)$ as regards severity of poisoning.
Figure 2: Motives for suicide

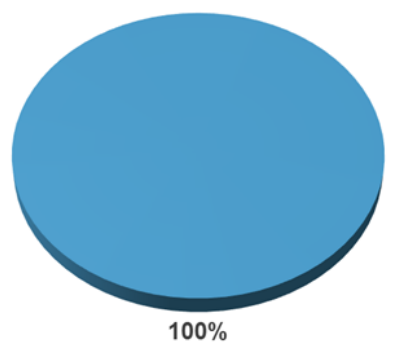

Figure 2: Distribution of Suicidal Poisoning Cases Admitted to Menoufia Poison Control Center (MPCC) at Menoufia University Hospital over two years $(2013 \& 2014)$ as regards motives for suicide.

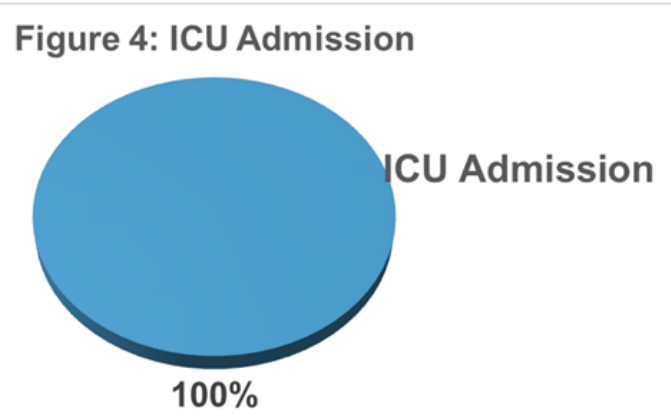

Figure 4: Distribution of Suicidal Poisoning Cases Admitted to Menoufia Poison Control Center (MPCC) at Menoufia University Hospital over two years (2013\&2014) as regards percentage of Intensive Care Unit (ICU) admission.

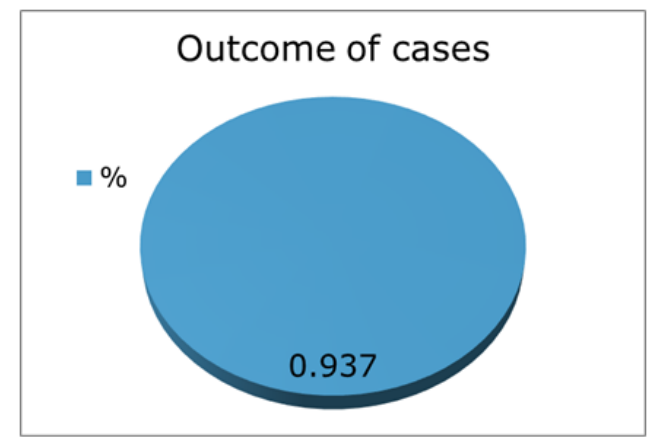

Figure 5: Distribution of Suicidal Poisoning Cases Admitted to Menoufia Poison Control Center (MPCC) at Menoufia University Hospital over two years $(2013 \& 2014)$ as regards outcome of these cases.

\section{Discussion}

This study reflects the prevalence of suicidal poisoning cases among all poisoned cases admitted to Menoufia Poison Control Center (MPCC) at Menoufia University Hospital over two years (From the 1 st of January 2013 to the end of December 2014).

The suicidal poisoning rate in this study was $28.46 \%$ of all arrived poisoning cases (1240 cases), this percentage is noticed to be increased comparing with the rate at the previous study in 2005 in the same center (was $12.53 \%$ of all poisoning cases).
The present study showed that the suicide poisoning were more common among females, with female: male ratio of 2.8: 1 . This may be explained by the increasing social and familial stress on females in the developing countries. Low education and low employment status for females also play a role. These results are similar to Pires et al., ( 2012) who found that $70 \%$ of the suicide attempts were females. On the contrary, Abdel Moneim et al.' (2012) studied suicidal 
rates in Assiut, Egypt and found that less than 42\% were females.

In present study the most vulnerable age group was 18-30 years old, this may be due to social problems such as unemployment and increase in drug abuse, in addition to emotional and psychological changes at this age group. Badawy et al., (2005) in his Study of self delebrate poisoned cases admitted to Menoufia Poisoning Control Center,Egypt, supported these findings and found that the highest vulnerable group was 19-36 years. Vijayakumar (2004) in his study on suicide prevention in developing countries also found that the highest suicidal rate was more common among people below 30 years in developing countries. Najafi et al., (2014) in his study in Iran, found that $55.5 \%$ of attempted self-poisoning were in the 20-29 year age group. Gad El-Hak et al., (2009) supported these results in his study in Port Said city in Egypt, as they found that the most vulnerable age group was 20-30 years.

As regards the residence in our study, suicidal poisoning cases came more from urban areas (57\%) than from rural areas (43\%), this may be due to stressful life and weak family ties in urban areas, in contrast to urban areas, the social and religious considerations that are still respected. Prajapati et al., (2012) in his study in Ahmadabad, Pakistan, found that suicidal poisoning rates are higher in urban area (more than 50\%), while Badawy et al.,(2005) in his study in Menoufia Poisoning Control Center,Egypt, found that the percentage nearly the same.

In present study, the single marital status constituted about two-thirds of cases, this can be explained by the stress of loneliness leading to higher risk of psychiatric disorders. This findings are similar to the results found by Pire MC et al.' (2012) and EbruTurhan et al., (2011) in his study in Hatay, Turkey.

Family conflict was the most common cause (45.56\%). Educational motive for suicide poisoning attempts was significantly more common among females, while unknown motive were significantly more common among males as many male patients refused to report the cause. As regards to age, educational motive was significantly the most common one at the age group 7-18 years (age of education), while the family conflict was significantly the most common motive for poisoning suicide attempt at the age groups 18-30 years as this is the age of teenager and early marriage. Farzaneh et al.,(2010) in his study in Tehran, Iran, also found that family conflict was significantly the most common precipitation for suicide attempt (54.4\% of cases), Goren et al., (2003) in his study in Turkey also found that. This is not in agreement with Badawy et al., (2005) as he found that emotional motives for suicide significantly increase in female aged 7-19 years.

Pesticide is the most commonly used poisonous agent for attempting suicide (45.32\% of all cases) due to its availability at a cheap price in this area. Males use pesticides significantly more than females, due to the fact that Menoufia governorate is considered a mainly agricultural area with the majority of its male population work in agriculture. Females significantly use drugs (bronchodilators and oral hypoglycemic drugs) more than males for attempting suicidal. Hassan et al, in the study of Pattern of Suicidal Methods Used in Minoufia, Gharbiya and KafrElshekh Governorates (2008-2012), concluded that ingestion of pesticide was the most common method of attempted suicide (70.8\%) in both males and females in Menoufia, Gharbiya and KafrElshekh Governorates in Egypt . Gunnell and Eddleston in their study on suicide by intentional ingestion of pesticides in developing countries (2003), also concluded that pesticides are more commonly ingested in developingworld. In contrast, Schmidtke et al., (2004) in the study on suicidal Behaviour in Europe concluded that self-poisoning in developed countries is most commonly done with drugs. Also Farzaneh et al., in Tehran, Iran (2010), stated that pharmaceutical preparations were the most commonly employed suicidal agents as they ingested in $87.5 \%$ of studied cases.

In present study, most cases were completely cured (93.7\%). The mortality rate was 2.9\%. 69.45\% of deaths were caused by pesticide poisoning. An earlier study in the same center (MPCC) by Badawy S et al., (2005) showed a mortality rate of $0.86 \%$. This rise in mortality rate can be explained by the use of more lethal substances, recently, such as zink phosphide (which constituted $72 \%$ of deaths due to pesticides poisoning). Eddleston et al., (2002) in their study in the developing world, also concluded that deaths from pesticide poisoning make a major contribution in developing nations.

Mortality rate in this study (2.9\%) is less than in other studies outside Egyptian country as Logaraj et al., (2005) in Tamilnadu. Indian who reported that, the proportion of fatal suicidal attempts was $17.86 \%$ and also Kumar (2000) in India, who reported $10 \%$ mortality in his study.

These findings were in contrast with the study done by Flanagan and Rooney (2002), as they reported that, analgesics and antidepressants are the substances most frequently ingested in fatal overdose in England. In 2005, Kapur et al., found that paracetamol was the drug most commonly causing in-hospital death in England.

\section{Conclusion}

The present study is a retrospective one, included 1240 self-poisoning cases attended Menoufia Poison Control Center (MPCC) at Menoufia University Hospital over two years from first of January 2013 to the end of December 2014.

The main risk factors of suicide poisoning are female sex, age group 18-30 years, urban residence, single persons. The most commonly used substance in committing suicide was pesticide, there are different motives for suicide poisoning the most common one was family conflict, according to the poisoning severity score most cases were mild.

\section{Recommendations}

Further prospective studies and regular detailed hospital records are needed all over the Egyptian 
governorates to more understand the self-poisoning problem and try to find effective solution to this problem and find more safe pesticides and to be sold under close restriction.

Health awareness about the dangers of toxicity of drug overdose and pesticides.

The psychiatric team must evaluate all cases of suicide in order to try to prevent further attempts

\section{References}

Abdel Moneim WM; Yassa HA; George SM (2012): Suicide trends in Upper Egypt. J Forensic Sci. 57(5):1247-1251.

Aggarwal N (2009): Rethinking suicide bombing. Crisis.30(2):94-97.

Badawy S; Amin S; Hammad S; Girgs N; El-Haddad A (2005): A Study of self deliberate poisoned cases admitted to Menoufia pisoning control center MPCC over one year. Ain Shams $J$ Forensic Med ClinToxicol. IV:138-158.

Hassan DA; Ghaleb SS and ARZ (2015): Pattern of Suicidal Methods Used in Minoufia, Gharbiya and KafrElshekh Governorates (2008-2012). J Forensic Res. 6(1).

Eddleston M; Karalliedde L; Buckley N, et al., (2002): Pesticide poisoning in the developing world-a minimum pesticides list. Lancet. 360(9340):1163-1167.

Farzaneh E; Mehrpour O; Alfred S; Moghaddam HH; Behnoush B; Seghatoleslam T

.( 2010): Self-poisoning suicide attempts among students in Tehran, Iran. PsychiatrDanub. 22(1):34-38.

Flanagan RJ and Rooney C ( 2002): Recording acute poisoning deaths. Forensic Sci Int. 128(12):3-19.

Gad ElHak SA; El-Ghazali AM; Salama MM; Aboelyazeed AY(2009): Fatal suicide cases in Port Said city, Egypt. J Forensic Leg Med. 16(5):266-268.

Goren S; Gurkan F; Tirasci Y; Ozen S(2003): Suicide in children and adolescents at a province in Turkey. Am J Forensic Med Pathol. 24(2):214-217.

Gunnell D and Eddleston M (2003): Suicide by intentional ingestion of pesticides: a continuing tragedy in developing countries. Int J Epidemiol. 32(6):902-909.

Gunnell DJ; Brooks J and Peters TJ (1996): Epidemiology and patterns of hospital use after parasuicide in the south west of England. J Epidemiol Community Health.50(1):24-29.
Hawton K and van Heeringen K. Suicide (2009): Lancet. 373(9672):1372-1381.

Kapur N; Turnbull P; Hawton K, et al. , (2005 ): Selfpoisoning suicides in England: a multicentre study. QJM. 98(8):589-597.

Kumar SP (2000): A descriptive analysis of methods adopted, suicide intent and causes of attempted suicide. Indian $J$ Psychol Med.23(1):47-55.

Logaraj M; Ethirajan N; Felix J; Roseline F (2005): Suicidal Attempts Reported at a Medical College Hospital in Tamilnadu. Indian $J$ Community Med. 30(4):136-137.

Michel K; Ballinari P; Bille-Brahe U, et al.,( 2000): Methods used for parasuicide: results of the WHO/EURO Multicentre Study on Parasuicide. Soc Psychiatry Psychiatr Epidemiol.35(4):156-163.

Najafi F; Beiki O; Ahmadijouybari T, et al.,( 2014): An assessment of suicide attempts by selfpoisoning in the west of Iran. J Forensic Leg Med.27:1-5.

Person HE; Sjoberg GK; Haines JA; Pronzuk J (1998): Poisoning Severity score. Grading of acute poisoning. J ToxicolClinToxicol. 36(3):20513.

Pires MC da C; Raposo MCF; Pires M; Sougey EB; Bastos Filho OC (2012): Stressors in attempted suicide by poisoning: a sex comparison. Trends psychiatry Psychother.34(1):25-30.

Prajapati K; Merchant S and Patel P (2012):Trends of Suicidal Poisoning In Ahmadabad Retrospective Study. 1( 1).

Schmidtke A; Weinacker B; Löhr C, et al., (2004): Suicidal Behaviour in Europe: Results from the Who/Euro Multicentre Study on Suicidal Behaviour. Hogrefe Publishing; 2004.

Turhan E; Inandi T; Aslan M, Zeren C (2011): Epidemiology of attempted suicide in Hatay, Turkey. Neurosciences (Riyadh). 16(4):347352.

Värnik P (2012): Suicide in the world. Int J Environ Res Public Health. 9(3):760-771.

Vijayakumar L(2004): Suicide prevention: the urgent need in developing countries. World Psychiatry.3(3):158-159.

WHO (2012): WHO report suicidal statistics. 2012.ISBN $978 \quad 92 \quad 4 \quad 156444 \quad 1 \quad$ (NLM classification: WA 900.1).

WHO (2011): WHO report suicidal statistics. 2011.ISBN $97892 \quad 4 \quad 156419 \quad 9 \quad$ (NLM classification: WA 900.1). 
الملخص العزبيى

\section{دراسة لحالات التسمم المتعمدة بغرض محاولة الانتحاروالتى ادخلت مركز علاج التسمم والإدمان بجان بامعة

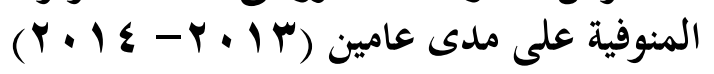

\section{علا عبد الهادى منصور و فاطمة شعبان قنديل}

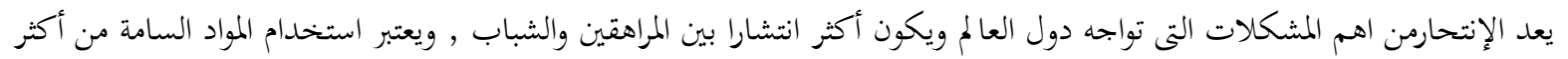

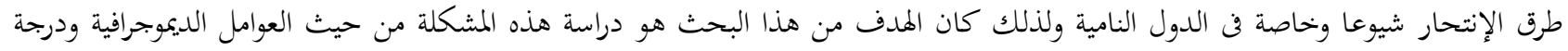

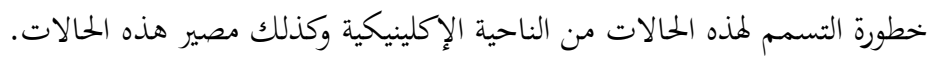

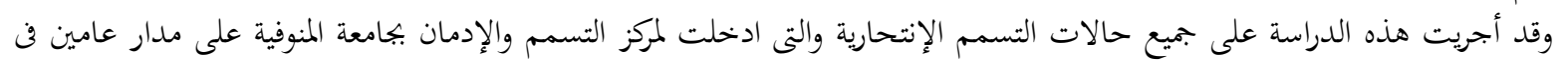

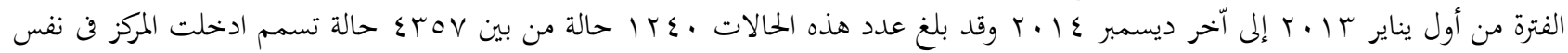

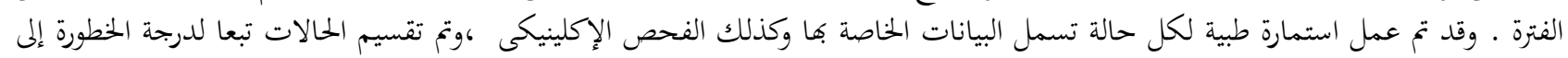

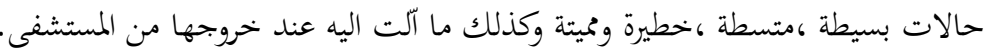

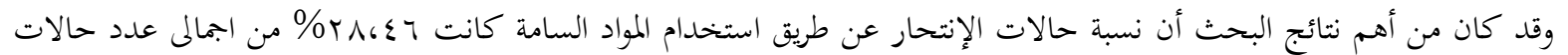

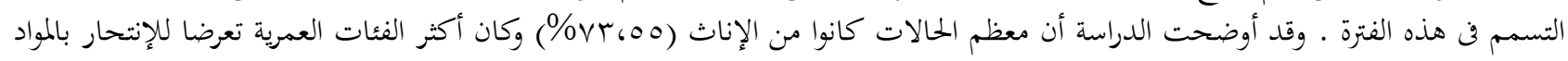

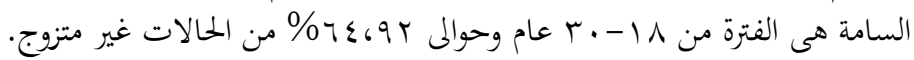

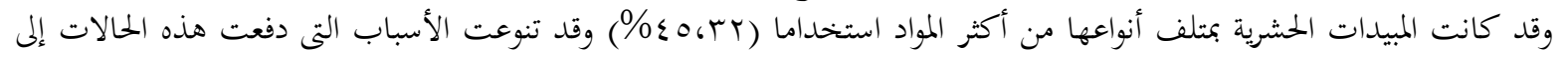

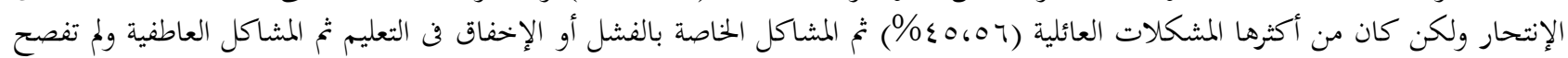

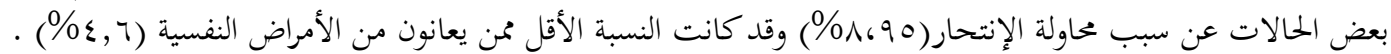

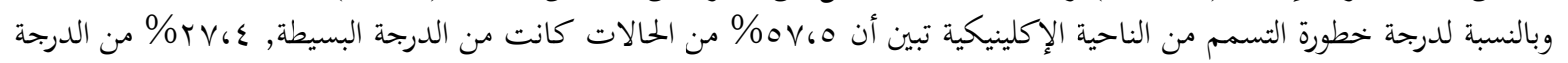

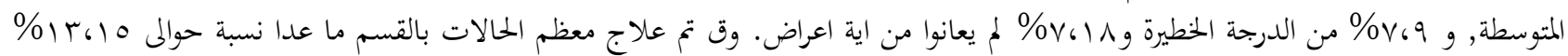
تطلب علاجها دخولما للعناية المركزة.

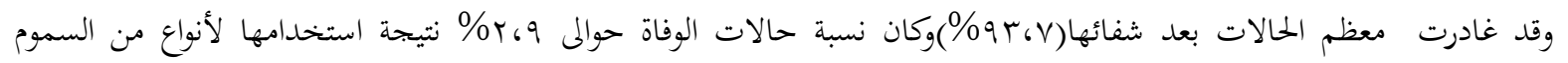
شديدة الخطورة ونظرا لتاخر وصولها للمستشفى.

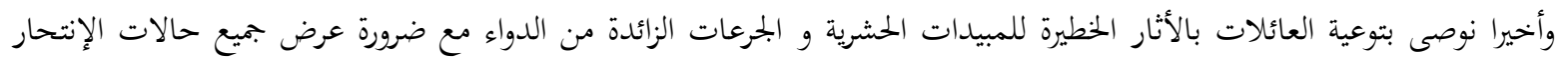

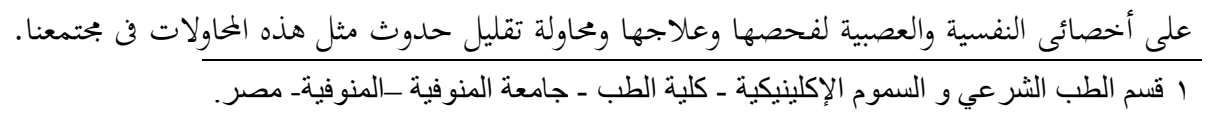

